\title{
THE RESEARCH OF THE BOILING CRISIS OF HYDROUS SOLUTION LITHIUM BROMIDE
}

\author{
Nina V. Mironova ${ }^{1,}$, , Vladimir S. Morozov ${ }^{2}$, Sergey L. Elistratov ${ }^{1,2}$, and Roman S. Ratkov ${ }^{1}$ \\ ${ }^{1}$ Novosibirsk State Technical University, 630073 Novosibirsk, Russia \\ ${ }^{2}$ Institute of Thermophysics SB RAS, 630090 Novosibirsk, Russia
}

\begin{abstract}
Experimental and theoretical investigate the process of nonisothermal desorption of water solutions of lithium bromide in the spheroidal state on the horizontal heating surface. It was established experimentally that on reaching average weight of the salt concentration of $15 \div 23 \%$ and $32 \div 34 \%$, respectively, at a temperature of the heating surface 400 and $600{ }^{\circ} \mathrm{C}$, the solution direct contact with the heating surface and the boiling crisis is replaced by a crisis mode of "explosive" boiling up. Some possible causes of the phenomenon were investigated: decrease in the thickness of the vapor layer with increasing concentration, the effect of temperature of the heating surface, radiation heating and capillary instability of interphase.
\end{abstract}

\section{Problem Statement}

For the development of absorption thermotransformers with the multi-stage regeneration is necessary to know the physical dependency of the desorption of water solutions of lithium bromide at high temperatures of the heating surface.

Known $[1,2]$ that evaporation of fluids may occur in the boiling crisis conditions when they stably separated from the heating surface of thin steam film (fig. 1).

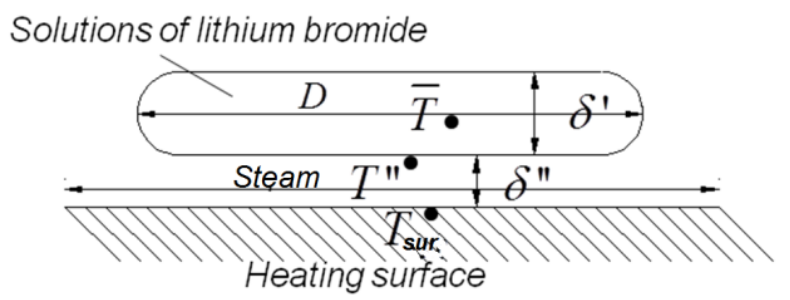

Fig. 1. Diagram evaporation solution of $\mathrm{LiBr}$ in the spheroidal state (bubble free spheroid).

In this case, the heat transfer from the heating surface to the fluid takes place by heat conduction and radiation through separating their thin resilient layer of steam. The expression the determination of his thickness in relation to the pure liquids, such as water, of an evaporating into spheroidal state on the horizontal heating surface, obtained in [2]:

\footnotetext{
* Corresponding author: mironovaNina@inbox.ru
} 


$$
\delta^{\prime \prime}=\frac{1}{\sqrt[4]{32 \cdot \xi^{2}}} \cdot \sqrt{\frac{\lambda^{\prime \prime}\left(T_{\text {sur }}-T^{\prime \prime}\right) D}{r\left[1+c\left(T^{\prime \prime}-\bar{T}\right) / r\right]}} \sqrt[-4]{g \delta^{\prime} \rho^{\prime} \rho^{\prime \prime}}
$$

where: $\xi$ - coefficient of discharge, which takes into account the shape of the periphery of the flat spheroid and the nature of its steam flow; $\lambda$ ", $\rho$ " - thermal conductivity and density of saturated steam, respectively; $T_{\text {sur }}, T$ " и $\bar{T}$ - heating wall temperature, temperature of the saturated vapor in the lower part spheroid and the average temperature of the spheroid, respectively; $D, c, \rho^{\prime}, \delta^{\prime}$ и $r$ - respectively diameter, specific heat capacitance, density, thickness and specific heat of evaporation of liquid. In the derivation of (1) does not take into account radiation heating and evaporation from the top and side surfaces of the flat spheroid, with a decrease in the values of $D$, its thickness $\delta^{\prime}=$ const in the process of evaporation. Continuous steam film under evaporating in the spheroidal state clean liquid is stored until their complete evaporation. For water is possible take $\xi=0.143$.

The solution (1) has a physical limitations. According to (1) the thickness of the layer of steam $\delta^{\prime \prime}$ depends on $D$, and can take any value. Experimentally established [1] that the output of steam is carried out not only at the peripheral part of a spheroid, but also through the layer of liquid in the form of vapor bubbles. The average distance between periodically pop bubbles at the boil in a large volume [3] and on evaporation of in the spheroidal state of clean liquids $[1,4]$ can be defined as:

$$
L=2 \pi \sqrt{\frac{\sigma}{g\left(\rho^{\prime}-\rho^{\prime \prime}\right)}},
$$

where: $\sigma$ - capillary tension, $\rho$ ' и $\rho$ ” - density of the liquid and of steam, respectively.

\section{Results}

Provided that $D \approx L$ expression (1) allows us to estimate $\delta^{\prime \prime}$ for real processes of evaporation of liquids in the spheroidal state.

It was established experimentally [4], in contrast to the previously investigated the processes of evaporation in the spheroidal state clean liquids, the desorption process (evaporation) bubble free spheroids aqueous solutions of lithium bromide on the horizontal heating surface is completed "explosive" boiling up (fig.2) with the destruction of the continuity of the vapor film. At the time of "explosive" boiling up critical value weight concentration salt of $\varphi_{\mathrm{KP}}=m_{\mathrm{LiBr}} /\left(m_{\mathrm{H}_{2} \mathrm{O}}+m_{\mathrm{LiBr}}\right) \approx 15 \ldots 23 \%$ for $T_{\mathrm{ST}}=400^{\circ} \mathrm{C}$.

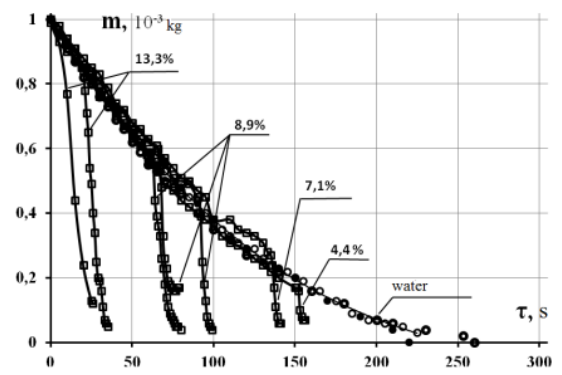

Fig. 2. The time variation of the mass of bubble free spheroids water and aqueous solutions of $\mathrm{LiBr}$ for various initial weight concentrations salt $\varphi_{0}=13.3 \div 4.4 \%$ for $T_{\mathrm{ST}}=400^{\circ} \mathrm{C}$. 
Obtained in this paper the experimental data (fig.3, No. 8-11 video footage) for bubbly spheroids aqueous solution of lithium bromide also confirm the "explosive" nature of the desorption process at achievement values $\varphi_{\mathrm{KP}}=32 \ldots 34 \%$ and its further development (No. 12-14 video footage) on the heating surface for $T_{\mathrm{ST}}=600^{\circ} \mathrm{C}$. Desorption process was completed by evaporation of the solution rests on the heating surface (video frame No. 15). Part of the solution in the form of a splashes at "explosive" boiling up flew in an experimental plot area inaccessible for weighing. In the process experiments performed synchronous in time $\tau$ mass determination solution $m$ with an accuracy of $0.01 \mathrm{~g}$ and a temperature of the heating surface $T_{\mathrm{ST}}$ by a thermocouple, located in the heater at a distance of $1 \mathrm{~mm}$ from the heating surface. Given the known initial the mass of salt in the solution $m_{0}=2.14 \mathrm{~g}$ is determined by its current values.

It is noteworthy that obtained in our experiments for bubbly and bubble free spheroids values $\varphi_{\mathrm{KP}}$ is 2-3 times fewer than concentrations of crystallization of aqueous solutions of lithium bromide [5].

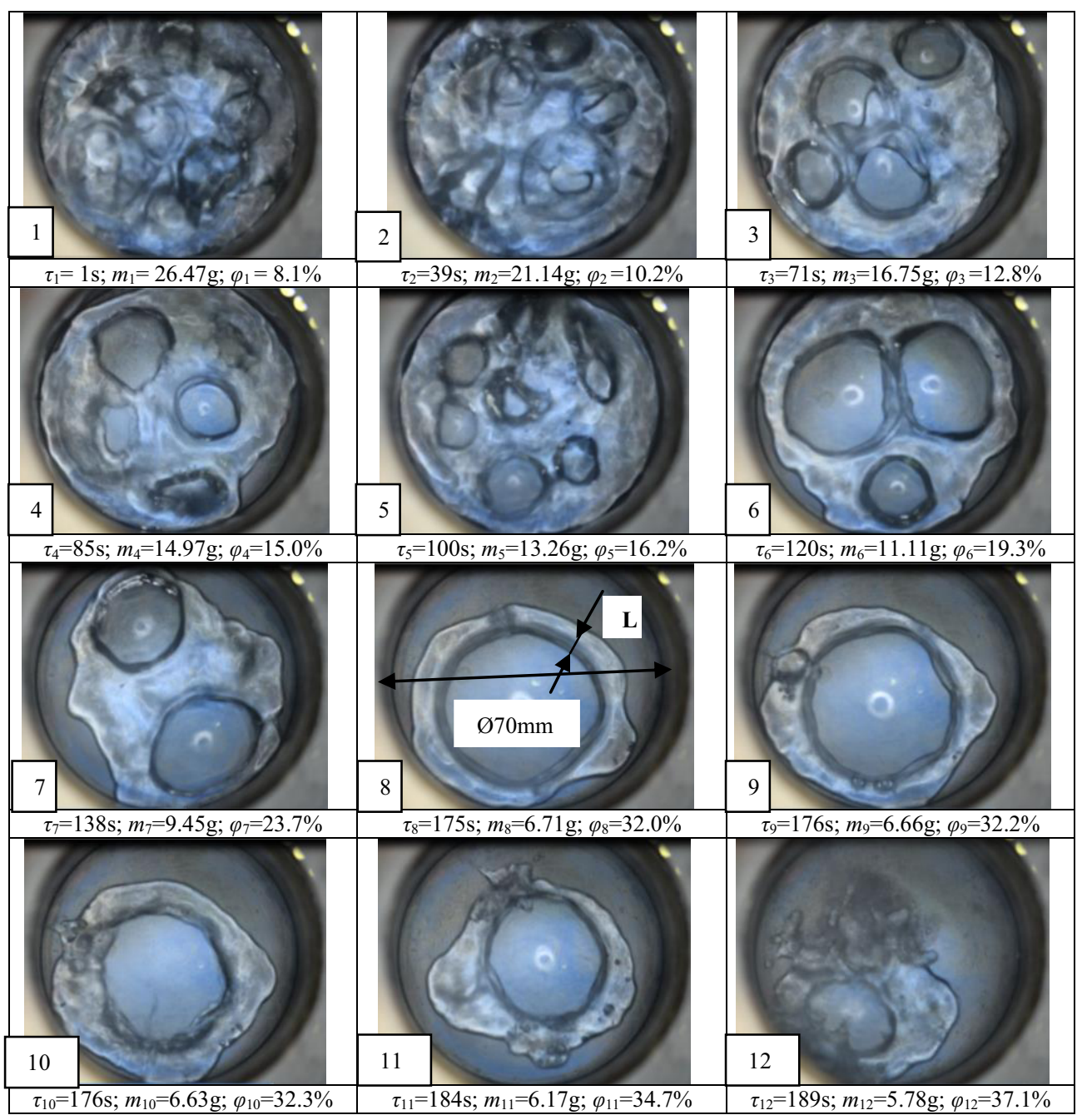




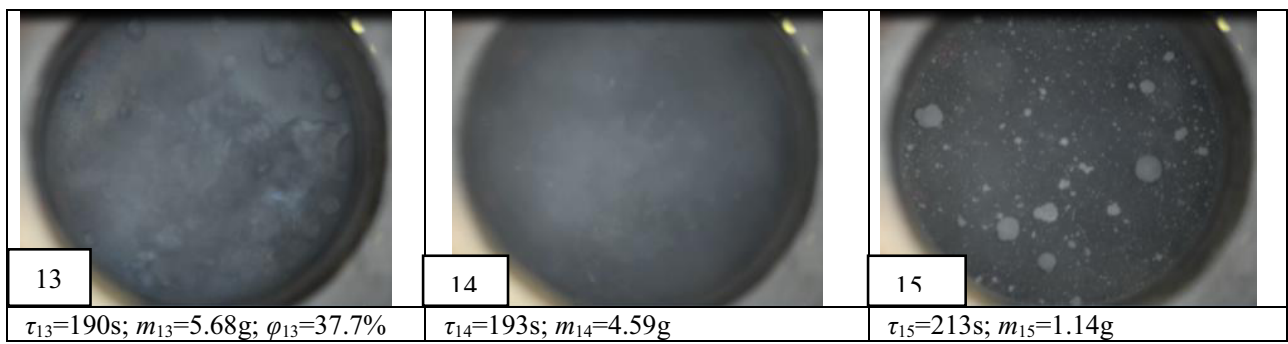

Fig. 3. The picture of desorption aqueous solution of $\mathrm{LiBr}$ on the heated surface with a temperature of $600{ }^{\circ} \mathrm{C}$ (current time value $\tau$, the mass $m$ and the weight concentration of salt in the solution $\varphi$ are indicated with the beginning of filming).

Theory and experimental data for the evaporation of clean liquids in the spheroidal state can not explain the phenomenon of the "explosive" boiling up.

Presented our vision of the phenomenon. With increasing $\varphi$ changes the values $c, r, \bar{T}$ and other parameters of the process in the expression (1). Based on the data about the characteristics of water and salt solutions [4] provided that $T^{\prime \prime}=\bar{T}, \delta^{\prime}=4 \cdot 10^{-3} \mathrm{~mm}$ и $\xi=0.143$ were estimated values $\delta$ ". The average value of $D \approx L=4 \cdot 10^{-3} \mathrm{~m}$ is determined based on measurement at the initial moment of contact solution with the heating surface (fig. 3 , video frame No. 8). From the presented in fig. 4 and 5 curves shows that the $\delta^{\prime \prime}$ tends to increase with an increasing $T_{\mathrm{ST}}$ and decrease with increasing $\varphi$. The difference values of $\varphi_{\mathrm{KP}}$ at a $T_{\mathrm{ST}}$ $=400{ }^{\circ} \mathrm{C}$ (fig. 2) and $T_{\mathrm{ST}}=600{ }^{\circ} \mathrm{C}$ (fig. 3) is explained by the increase in $\delta$ " with increasing $T_{\mathrm{ST}}$.

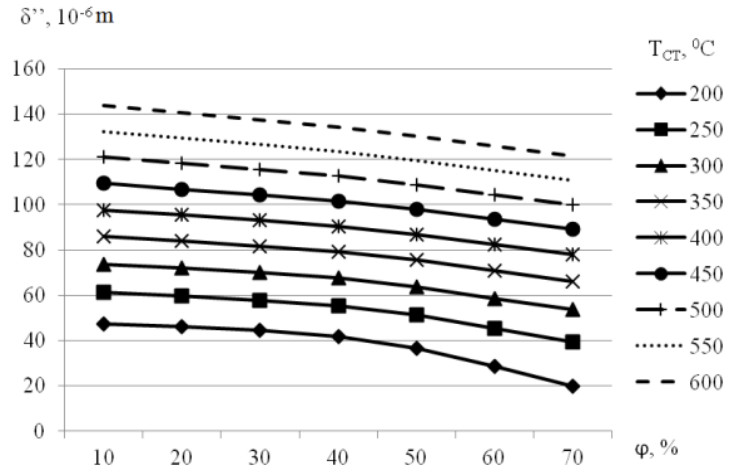

Fig. 4. Dependence of the thickness vapor layer on the temperature of the heating surface.

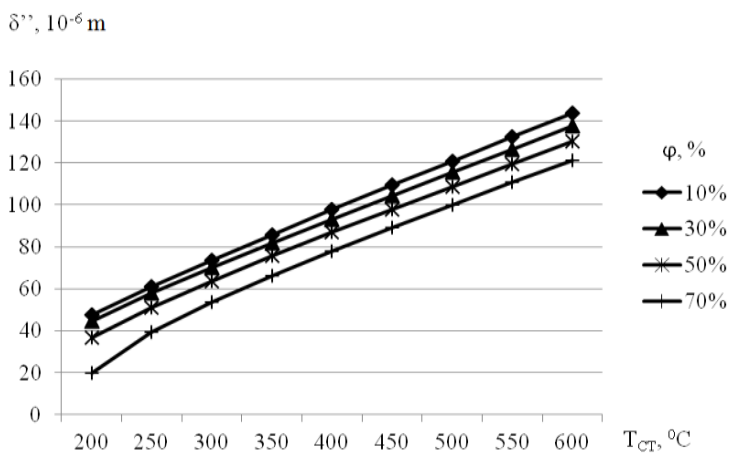

Fig. 5. Dependence of the thickness vapor layer on the concentration of the aqueous solution of lithium bromide. 
In defining the degree of stability of the boiling crisis (evaporation of the liquid in the spheroidal state) is determined by the vapor layer's thickness $\delta$ " under the evaporating liquid spheroid. When decreased as a result of the wave of instability interfacial surface of the liquid will probably solution direct contact with the heating surface. Thus, the contact mechanism "explosive" boiling up is triggered.

In the (1) unaccounted factor is the heating of the solution at the expense of radiant heat transfer. Its maximum value at the initial time "explosive" boiling up (fig.3, No. 8 and 11 video footage) can be determined by the expression:

$$
q_{1}^{\mathrm{MAX}}=\varepsilon \cdot \sigma \cdot\left[T_{\mathrm{ST}}{ }^{4}-\left(T^{\prime \prime}\right)^{4}\right] \cdot F_{\mathrm{SF}},
$$

and a minimum value corresponding to the flow of radiant from the heating surface to the bottom of the spheroid, the expression:

$$
q_{1}^{M I N}=\frac{\sigma \cdot\left[T_{\mathrm{ST}}^{4}-\left(T^{\prime \prime}\right)^{4}\right]}{\frac{1}{\varepsilon_{\mathrm{ST}}}+\frac{1}{\varepsilon}-1} \cdot S .
$$

Here, $\varepsilon$ and $\varepsilon_{\mathrm{ST}}$ - emissivity factor surface of an aqueous solution of lithium bromide and heating wall material (titanium), respectively; $\sigma=5.67 \cdot 10^{-8} \mathrm{~W} / \mathrm{m}^{2} \cdot \mathrm{K}^{4} ; F_{\mathrm{SF}}$ and $S-$ respectively, the total area of the outer surface area of the solution and its projection on the heating surface, $\mathrm{m}^{2}$.

The total heat exchange capacity $q$, determined based on mass changes spheroid to 2.74 $\mathrm{g}$ in $37 \mathrm{~s}$ (fig.3, video footage No.7 and 8), is $163 \mathrm{~W}$, and according to (3) and (4) the contribution of radiant heat transfer amounted to $181.4 \ldots 42 \mathrm{~W}$. Consequently, the radiant heat transfer is able to provide additional heating of the spheroid and increase the thermodynamic instability of the solution, as a factor of "explosive" boiling up.

Thus, as a possible reason for the "explosive" fracture weighed portions of an aqueous solution of lithium bromide, which are in spheroidal state on the heating surface are general and local increase in concentration of the solution, existence of its own capillary instability of phase contacting area of the solution with the formation of surface waves, leading to reduction in the size of a thin layer of steam to dimensions irregularities the heating surface. An additional factor reinforcing this effect is overheating of the solution due to the radiant heat transfer.

\section{References}

1. V.M. Borishansky, K.M. Arefiev, I.I. Paleev, Tekhtilov R.T. Trudy, TSKTI [Proceedings of CKTI] 78-83, 62 (1962) [in Russian]

2. S.S. Kutayeladze, Atomizdat Publ. 416 (1979) [in Russian]

3. E.I. Nesis, Moscow Nauka Publ. 280, (1973) [in Russian]

4. S.L. Elistratov, V.E. Nakoryakov, N.I. Grigoryeva Research and development of the $S B R A S$ in the field of energy-efficient technologies (Nauka Publ., Novosibirsk 2009) [in Russian]

5. A.V. Baranenko, S.V. Karavan, O.A. Pinchuk, D.V. Karavan, Moscow, Pero Publ. 393 2014) [in Russian] 